\title{
Patients used the internet to transform their cancer experiences
}

Ziebland S, Chapple A, Dumelow C, et al. How the internet affects patients' experience of cancer: a qualitative study. BMJ 2004;328:564.

\section{$Q$ How do men and women with cancer talk about using the internet?}

\section{DESIGN}

Qualitative study using interviews collected for the DIPEx charity (www.dipex.org), which runs a website based on video, audio, and written clips from hundreds of interviews with patients.

\section{SETTING}

UK.

\section{PARTICIPANTS}

Using maximum variation sampling, 175 men and women 18-83 years of age who had been diagnosed with prostate, testicular, breast, cervical, or bowel cancer in the previous 10 years were recruited at different stages of disease through general practitioners, hospital consultants, support groups, and word of mouth.

\section{METHODS}

Individual narrative interviews were usually done in the respondents homes. Participants were asked to tell their own stories from the time they began to suspect they had a problem. The interviewer then used a set of semistructured questions to explore how and why information and support was accessed. Interviews were read and coded using both anticipated and emergent themes and analysed using constant comparison. Negative cases were sought and discussed.

\section{MAIN FINDINGS}

55 respondents directly accessed cancer information on the internet, and another $2 \mathrm{l}$ accessed the internet through friends or family. Those who accessed the internet talked about its distinctive and appealing characteristics: privacy and 24 hour availability. A participant with bowel cancer noted "...you haven't actually got to leave your house, it doesn't matter how you're feeing. You don't even have to get dressed: you can just, you know, log on and you can get the information." Other respondents noted that using the internet avoided the embarrassment of face to face or telephone interactions. Another appealing feature was that respondents could search for different types and levels of information when the need arose.

Timing and reasons for using the internet. Before visiting physicians: to discover the possible meaning of symptoms. During investigations: to seek reassurance that the correct tests were being done; prepare for the results; and improve the value of consultations. After diagnosis: to gather information about their cancer; interpret what health professionals said; seek advice on how to tell children; contact online support groups; seek second opinions; and tackle isolation. When choosing treatments: to gather information about treatment options and side effects, experimental treatments, research, and alternative or complementary treatments. Before treatment: to identify what to take to hospital, what would happen, and what to expect during recovery. Short term follow up: to prepare questions for doctors; gather information on side effects, diet, complementary treatment,

For correspondence: Dr S Ziebland, Department of Primary Health Care University of Oxford, Institute of Health Sciences, Oxford, UK. sue.ziebland@ dphpc.ox.ac.uk

Sources of funding: Citrina Foundation; Department of Health; NHS National Screening Programme; NHS Direct Online; Macmillan Cancer Relief. and benefits and finances; seek reassurance about symptoms; check that treatment was optimal; and identify perceived therapeutic benefits. Long term follow up: to share experience and advice; contact support groups and chat rooms; and campaign about the condition.

Respondents used the internet in 2 distinct ways to transform their roles and their involvement in health care. They described using the internet to check up on their doctor's responses and advice at all stages of the disease process. Reasons included being given contradictory advice; acknowledgment that it was difficult for doctors to keep up with state of the art medical information; to ensure that optimal treatment was given; and to identify preferred options. Respondents also described using the internet to display competence. The internet allowed respondents to gain, maintain, and display familiarity with a range of medical and experiential knowledge about their illness. Some seemed to suggest that seeking information was almost an obligation: “...if you haven't got a computer go down to an internet café - there is no excuse whatsoever for not finding out about testicular cancer or all the other things..."

\section{CONCLUSION}

Patients with cancer used the internet for various information and support needs throughout their illness in order to transform roles and change their involvement in health care.

\section{Commentary}

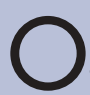

nline information seeking by patients increasingly must be acknowledged, understood, and supported by care providers. The study by Ziebland et al offers insight into how individuals with serious illnesses use information from the internet. The findings support Dupuits' ${ }^{\prime}$ assertion that the internet serves 5 main functions for healthcare consumers: providing and distributing information; supporting informed decision making; promoting health; exchanging information and providing community support; and increasing self care and managing demands for health services. The findings are also consistent with those of The Pew Internet and American Life Project, ${ }^{2}$ in that information reviewed on the internet affected respondents' decisions about going to a physician, selecting a treatment, and identifying questions to ask physicians. Evidence suggests that well informed individuals are better able to manage their health and treatments and have less anxiety and depression, fewer exacerbations of conditions, and fewer hospital admissions.

Ziebland et al acknowledge that many important questions about the internet are beyond the scope of a qualitative interview. However, the study offers important information for nurses by revealing how patients with serious illnesses use the internet to seek information and discussing the effect on patient confidence and participation throughout assessment, diagnosis, treatment, and follow up of an illness. JoAnn Mick, RN, MSN, MBA University of Texas MD Anderson Cancer Center and Texas Womans' University Houston, Texas, USA

1 Dupuits FM. The effects of the Internet on pharmaceutical consumers and providers. Disease Management \& Health Outcomes 2002;10:679-91.

2 Fox S, Rainie L, Horrigan J, et al. The online health care revolution: how the web helps Americans take better care of themselves. Washington, DC: The Pew Internet \& American Life Project, 2000. hitp://www. pewinternet.org/ $\mathrm{PPF} / \mathrm{r} / 26 /$ report_display.asp

3 Caress AL. Giving information to patients. Nurs Stand 2003;17:47-54. 